\title{
Harea berdeen erabilera morteroen eroankortasun termikoa aldatzeko
}

\author{
(Use of Green Foundry Sand to change the thermal properties \\ of mortars)
}

\author{
Roque Borinaga-Treviño*, Aimar Orbe, Javier Canales, Jesús Cuadrado \\ Ingeniaritza Mekanikoa saila, Bilboko Ingeniaritza Eskola, \\ Euskal Herriko Unibertsitatea (UPV/EHU)
}

\begin{abstract}
LABURPENA: Eraikuntza-sektorean hormigoiak eta morteroak dira gehien erabiltzen diren eraikuntza-materialak, eta lehengai natural asko kontsumitzen dituzte, beren osagai nagusiak (harea eta zementua) harrobietatik lortutako harri naturalak tratatuz lortu behar baitira. Baliabide naturalen erabilera murrizteko helburuarekin, morteroetan galdaketako harea birziklatua erabiltzeak propietate fisiko, termiko eta mekanikoetan duen eragina aztertzen da artikulu honetan. Morteroetan normalean erabiltzen den kareharri-harearen ordez, galdaketako harea berdea erabili da, hainbat ehunekotan (\% 0, \% 25, \% 50, \% 75 eta \% 100), eta mortero gogortuen porositatea, ultrasoinuen hedapen abiadura, eroankortasun termikoa, bero espezifiko bolumetrikoa, eta makurdura- eta konpresio-erresistentziak neurtu dira. Emaitzak aztertuta, argi dago galdaketako harea berdeak duen bentonita-edukiaren eragina: ur gehiago behar duenez, handitu egiten du porositatea, eta murriztu egiten ditu eroankortasun termikoa, bero espezifiko bolumetrikoa eta erresistentzia. Hala ere, galdaketako harea berdearen erabilera bideragarria litzateke exijitu beharreko erresistentzia mekanikoa baxua denean eta morteroaren eroankortasun termikoa murriztea interesgarria denean. Adibidez, zolatu eta estalkietan erabil liteke, nibelatze-kapa moduan.
\end{abstract}

HITZ GAKOAK: harea berdea, galdaketa, morteroa, hormigoia, birziklatu, termikoa.

ABSTRACT: Being cementitious composites, such as concretes and mortars, the most consumed construction materials, there is a necessity to replace as much of the natural resources consumed as possible by more ecofriendly, industrial and construction by-products. This paper studies the use of green foundry sand as partial to total replacement of the usual, limestone sand used in mortars and as fine aggregates in concretes. With that in mind, limestone sand has been replaced by green foundry sand in different percentages -0\%-25\%-50\% $75 \%$ $100 \%$ - and density, porosity, ultrasonic pulse velocity, thermal conductivity, volumetric heat capacity, flexural strength and compressive strengths are evaluated. According to the results obtained, it is clear that the clay content of the green foundry sand increased the water required by the mix, increasing the mortar porosity and thus decreased the other properties. However, green foundry sand could still be used for the confection of mortars were mechanical strength are low enough, for example, as evening layer on roofs and slabs.

KEYWORDS: green sand, foundry, mortar, concrete, recycle, thermal.

* Harremanetan jartzeko / Corresponding author: Roque Borinaga-Treviño, Ingeniaritza Mekanikoa Saila, Bilboko Ingeniaritza Eskola, Euskal Herriko Unibertsitatea (UPV/EHU). Helbidea: Torres Quevedo plaza, 1 (48013 Bilbo). - roque.borinaga@ ehu.eus - https://orcid.org/0000-0002-0910-4186.

Nola aipatu / How to cite: Borinaga-Treviño, Roque; Orbe, Aimar; Canales, Javier; Cuadrado, Jesús (2022). «Harea berdeen erabilera morteroen eroankortasun termikoa aldatzeko»; Ekaia, ale berezia 2022, 63-74. (https://doi.org/10.1387/ekaia.23144).

Jasotze-data: 2021, urriak 26; Onartze-data: 2021, abenduak 28

ISSN 0214-9001 - elSSN 2444-3255 / (c) 2022 UPV/EHU

cc)()으 Lan hau Creative Commons Aitortu-EzKomertziala-LanEratorririkGabe 4.0 Nazioartekoa

(c) 


\section{SARRERA}

Industria- eta eraikuntza-sektoreetan geroz eta lehengai gehiago kontsumitzen direnez, jasangarritasunak garrantzi handia hartu du azken urteotan. Eraikuntza-sektorean, hormigoiak eta morteroak dira gehien erabiltzen diren eraikuntza-materialak $[1,2]$, eta lehengai naturalez osatuta daude gehienbat, beren osagai nagusiak (harea eta zementua) harrobietatik lortutako harri naturalak tratatuz lortzen baitira. Hori dela eta, hormigoiak eta morteroak fabrikatzeak duen karbono-aztarna murrizteko, bi alternatiba nagusi daude: zementuan Portland klinkerraren erabilera murriztea, baliabide naturalak eta ekoizpen-energia murrizteko, eta harea naturalen erabilera murriztea. Bi kasuetan, industria- eta eraikuntza-sektoreetatik lortutako hondakinez ordezkatzea izango da helburu nagusia.

Horrela, zementuz osatutako material konposatuetan azpiproduktu ugari sar daitezke bai harea, bai legarra, bai zementua ordezkatzeko, jatorrizko propietate fisiko, termiko eta mekanikoak berdinduz edota hobetuz. Industriatik lortutako hainbat azpiprodukturen erabilera aztertu duten hainbat lan daude [3-9], non txikitutako partikulak, zuntzak, hauts polimeroak, eraikuntzako hondakin solidoak, eta abar zementua, harea edota legarra ordezkatzeko edota errefortzu gisa erabili diren. Testuinguru honetan, erabiltzen ez diren pneumatikoek ingurumenean duten eragin negatiboa handia da, gehienek zabortegietan bukatzen baitute. Hortaz, pneumatikoak birrindu eta legar gisa erabil daitezke hormigoietan, hobetu egiten baitute beren moteltzea, eta trenbideetan zeharragak egiteko erabil litezke [3, 4]. Zerrautsa eta paper-lohia gehituz, aldatu egin daitezke mortero eta hormigoien propietate termikoak, beren propietate mekanikoak mantenduz, eraikuntzen estalkien isolamendu termikoa hobetzeko [5]. Metalurgia-siderurgia sektorean sortutako zepa beltzak legarra ordezkatzeko erabili izan dira hormigoiak egiteko egitura askotan (egituren zimenduetan edota itsas azpian bermatutako egituretan, adibidez), eta positiboak izan dira iraunkortasun-emaitzak [6]. Eraikuntzako eraispen-hondakinak ere ahalik eta gehien berrerabiltzea sustatzeko, gaur egungo legediak hormigoietan harea birziklatuak erabiltzea ahalbidetzen du [8], baina ez da lortu 2020rako jarritako berrerabiltze-mailara heltzerik [9].

Ikerketa honetan, galdaketa-prozesuan erabilitako harea berdearen berrerabilera aztertzen da, mortero eta hormigoietan erabilitako harearen ordez. Galdaketa-industrian moldeak egiteko erabiltzen den harea-bolumen guztiaren \% 90 harea berdeak dira. Kalitate altuko silize-harea da gehienbat, pisu totalaren \% 85-95 osatzen baitu. Aglutinatzaile gisa, \% 4-10ean, bentonita-buztina gehitzen zaio, bentonitaren propietate tixotropikoak erraztu egiten baitu moldeari forma ematea. Galdaketa-prozesuan sortutako piezak moldetik ateratzeko, apurtu egin behar dira moldeak. Molde horiek berriro birrindu eta harea berdea molde berriak egiteko erabili ohi da, bere 
hasierako propietateak galtzen dituen arte, harea berdeak hondakin bihurtuz. Hondakin horien kudeaketa ulertzeko, interesgarria da Euskadiko datuak aztertzea, Espainia-mailan garrantzi handia dute eta. Egindako analisiaren arabera, Espainian dauden 55 galdaketa-instalazioetatik 32 Euskadin daude kokatuta [10]. Azken urteotan, harea berdearen balorizazioaren gorakada argia gertatu da, gehienbat zementuaren sektorean. 2016an sortutako harea berde hondakinaren \% 43 birziklatu egin da; hala ere, ehuneko hori igotzea komeni da, gehiengoak oraindik ere hondakindegietan bukatzen baitu.

Mortero eta hormigoietan harea berdea erabiltzea ez da berria, eskura dauden artikulu anitzek argi uzten duten bezala [11-16]. Aipatzekoa da erresistentzia baxuko hormigoietan harea naturalaren ordez erabiltzea proposatzen dela oro har. Hormigoietan, harea berdeak duen bentonita-edukia dela eta, murriztu egiten da loditasuna, eta hobetu egiten da nahasketaren egonkortasuna. Loditasun berdina mantendu nahi izanez gero, ur gehiagorekin nahastu behar da, eta horrek porositatea handitzea eragiten du. Autore gehienek, hala ere, harea hormigoiak egiteko aproposa dela diote, baina harea naturalaren ordezkapen-maila baxuetan betiere (\% 20-30etik behera) $[12,14]$, hobetu egiten dituelako hormigoiaren erresistentzia eta iraunkortasuna, eta murriztu egiten duelako ura xurgatzeko ahalmena.

Bibliografia ugari dagoen arren, harrigarria da zein gutxi diren harea berdez eginiko mortero eta hormigoien propietate termikoak neurtzen dituzten artikuluak, gaur egun propietate horrek eraikuntzen efizientzia termikoa hobetzeko duen garrantzia kontuan hartuta. Hori dela eta, ikerketa honek morteroetan kareharri-harearen ordez harea berdea erabiltzeak propietate termikoetan duen eragina aztertzea du helburu. Horretaz gain, propietate fisiko eta erresistenteak ere neurtuko dira, lortutako morteroek izan ditzaketen erabilerak zehazteko.

\section{MATERIALAK ETA METODOLOGIA}

\subsection{Materialak}

Mortero guztiak egiteko, ura (u), superplastifikatzailea (sp), kareharri-harea (kh), galdaketako harea berdea (gk) eta zementua (z) erabili ziren. UNE-EN 197-1:2011 arauarekin bat datorren CEMII-B (L)/32.5R zementua erabili zen. Zementu horrek arauak ahalbidetzen duen kareharrifiller eduki altuena du, \% 35 artekoa izan baitaiteke. Zementu hori aproposa da zimenduetako hormigoiak eta igeltserotzako morteroak egiteko. Fabrikatzailearen fitxa teknikoaren arabera, zementuak 13,5 MPa-ko eta 42,5 MPa-ko konpresio-erresistentzia eskaintzen du 2 eta 28 egunetara, hurrenez hurren. Zementuaren eta uraren arteko gainazal-tentsioa murrizteko eta erabilitako ur-proportzioa minimizatzeko, BASFen Masterease 5038 
superplastifikatzailea gehitu zen nahasketa guztietan, zementuaren pisuarekiko \% 1ean. Horrela, mortero ia autotrinkotzaileak egitea ahalbidetu zen. Erabilitako kareharri-harea (kh) Lacilla SL enpresaren Sopuertako harrobitik dator, eta hormigoiak egiteko araudia betetzen du. Galdaketako harea berdea (gk), berriz, Fagor Ederlan enpresak Eskoriatzan duen fabrikatik dator. Harea sakonki aztertu zen FAGORek parte hartu zuen PISSAM eta VIAMOL proiektuetan, eta hondakin inerte ez-arriskutsu bezala sailkatu zen. Kareharriaren eta galdaketako harea berdearen propietateak 1. taulan laburbiltzen dira. Agregakinen granulometria, partikulen dentsitatea eta urxurgapena UNE-EN 933-1:2012 eta UNE-EN 1097-6:2014 arauei jarraituz lortu ziren.

1. taula. Erabilitako hareen propietateak.

\begin{tabular}{|c|c|c|c|c|c|c|c|c|}
\hline \multicolumn{9}{|c|}{ Kareharri-harea (kh) } \\
\hline Bahearen irekiera $[\mathrm{mm}]$ & 4 & 2 & 1,18 & 0,6 & 0,4 & 0,2 & 0,1 & 0,063 \\
\hline Igarotako masa [\%] & 100 & 92 & 68 & 44 & 35 & 22 & 15 & 13 \\
\hline Harea-partikulen itxuraz & \multicolumn{8}{|c|}{2.758} \\
\hline Ur-xurgapena [\% pisuan & \multicolumn{8}{|c|}{0,45} \\
\hline \multicolumn{9}{|c|}{ Galdaketako harea berdea (gk) } \\
\hline Bahearen irekiera [mm] & 4 & 2 & 1,18 & 0,6 & 0,4 & 0,2 & 0,1 & 0,063 \\
\hline Igarotako masa [\%] & 100 & 100 & 100 & 99 & 73 & 15 & 9 & 8 \\
\hline Harea-partikulen itxuraz & \multicolumn{8}{|c|}{2.629} \\
\hline Ur-xurgapena [\% pisuan & \multicolumn{8}{|c|}{4,5} \\
\hline
\end{tabular}

\subsection{Aztertutako morteroak}

Aztertutako morteroak 2. taulan zehazten dira. Erabilitako harea-proportzioen arabera bereizten dira morteroak. Mortero guztiek zementu:superplastifikatzaile:harea proportzio bera dute pisuan: 1:0.02:3. Hareaproportzioa definitzeko, mortero bakoitzean aldatu egin zen bi hareen pisu-proportzio erlatiboa. Horrela, bost $\mathrm{gk} / \mathrm{kh}$ proportzio aztertu ziren: 0/100 (kareharri-harea soilik, erreferentzia-morteroa izango zena), 25/75, 50/50, 75/25 eta 100/0 (galdaketako harea bakarrik zuena). Horretaz aparte, mortero bakoitzaren ur-proportzioa ere zehaztu zen, helburu zen 200-220 mm-ko loditasuna lortzeko, UNE-EN 1015-3/A2:2007 arauaren arabera neurtuta. Mortero bakoitzaren propietateak aztertzeko, $40 \times 40 \times 160 \mathrm{~mm}^{3}$-ko hiru probeta prismatiko sortu ziren UNE-EN 101510:2000 arauari jarraituz. Lehenik, abiadura baxuan nahastu ziren zementua eta hareak (minutu batez, gutxi gorabehera), nahasketa homogeneo 
bat lortu arte. Aldi berean, urari superplastifikatzailea gehitu zitzaion, eta nahastu egin ziren biak. Ondoren, ur- eta superplastifikatzaile-nahasketaren erdia gehitu zen, eta, minutu batez abiadura baxuan nahastu eta gero, uraren eta superplastifikatzailearen beste erdia gehitu zen, eta beste minutu batez nahastu. Ordurako nahasketak itxura homogeneoa zeukan arren, beste minutu batez abiadura altuan nahastu zen morteroa, nahasketan egon zitezkeen koskorrak desegiteko. Azkenik, nahasketa bi minutuz geldirik izan eta gero, berriro nahastu zen, abiadura handian, minutu batez.

2. taula. Lan honetan aztertutako morteroen dosifikazioak.

\begin{tabular}{cccccc}
\hline $\begin{array}{c}\text { Morteroa } \\
{[\mathrm{gk} / \mathrm{kh}]}\end{array}$ & $\begin{array}{c}\text { Zementua } \\
{[\mathrm{g}]}\end{array}$ & $\begin{array}{c}\text { Kareharri-harea } \\
{[\mathrm{g}]}\end{array}$ & $\begin{array}{c}\text { Galdaketako } \\
\text { harea berdea } \\
{[\mathrm{g}]}\end{array}$ & $\begin{array}{c}\text { Superplastifikatzailea } \\
{[\mathrm{ml}]}\end{array}$ & $\begin{array}{c}\text { Ura } \\
{[\mathrm{g}]}\end{array}$ \\
\hline $0 / 100$ & 600 & 1.800 & 0 & 12 & 300 \\
$25 / 75$ & 600 & 1.350 & 450 & 12 & 465 \\
$50 / 50$ & 600 & 900 & 900 & 12 & 520 \\
$75 / 25$ & 600 & 450 & 1.350 & 12 & 580 \\
$100 / 0$ & 600 & 0 & 1.800 & 12 & 620 \\
\hline
\end{tabular}

Nahasketa-prozesua amaitu eta gero, molde prismatikoen erdira isuri, eta, espatula baten bitartez, molde osoa bete eta leundu egin zen gainazala. Morteroz betetako moldeak plastikozko poltsetan sartu, eta bi egunez gogortzen utzi ziren, laborategiko giro-tenperaturan $\left(18-22^{\circ} \mathrm{C}\right)$. Azkenik, probetak moldetik atera, eta uretan $\left(18-22^{\circ} \mathrm{C}\right)$ murgildu ziren 26 egunez, araudiak ezarritako 28 egunak bete eta probeten saiakuntzekin hasi arte.

\subsection{Morteroen karakterizazioa}

Morteroek freskoan eta gogortutakoan dituzten propietateak zehazteko, hainbat saiakuntza egin ziren. Morteroaren nahasketa-prozesuarekin amaitu bezain laster, morteroak fresko zegoenean zuen loditasuna UNE-EN 1015-3/A2:2007 arauak deskribatutako prozedura jarraituz neurtu zen, astinduen mahaiaren bitartez. 28 egun geroago, gogortutako propietateak zehaztu ziren. Lehenik, morteroen itxurazko dentsitatea eta porositatea neurtu ziren, UNE-EN 1015-10:2000 arauari jarraituz. Saiakuntza horren ondoren probetak lehor zeudenez, beste saiakuntza guztiak mortero lehorrean egin ziren. Ondoren, ultrasoinuen hedapen-abiadura neurtu zen probetaren luzeran, Pundit PL200 ekipoa erabiliz, morteroek zuten porositate totalaren ebaluazio kualitatibo bat izateko. Saiakuntza hauetan ohikoa den bezala, baselina erabili zen $150 \mathrm{kHz}$-ko uhinak emititzen eta jasotzen dituzten piezoelektrikoen eta probeten arteko kontaktua hobetzeko. Ultrasoinuen hedapen-abiadura zehaztu eta gero, morteroen makurdura-erresistentzia 
neurtu zen, UNE-EN 1015-11:2000/A1:2007 arauari jarraituz. Kasu horretan, desplazamendua kontrolatuz egin zen saiakuntza, $0,5 \mathrm{~mm} / \mathrm{min}$-ko abiaduran. Ondoren, makurdura-saiakuntzak sortutako bi zati berdintsuak erabiliz, probeta bakoitzaren $\lambda$ eroankortasun termikoa eta $\mathbf{c}_{\mathbf{v}}$ bero espezifiko bolumetrikoa neurtu ziren, Hotdisk M1 ekipoarekin. Saiakuntza hori Gustafsson-ek [17] moldatutako energia-iturri plano trantsitorioan oinarritzen da. Saiakuntza a = 9,9 mm-ko diametroa duen Kapton 8563 disko-erresistentzia elektrikoa morteroaren bi probetaren artean zapaldu eta berotzean datza. Erresistentzia elektrikoak, berotzeaz aparte, tenperatura-igoera ere neurtzen du. Diskoaren tenperatura-igoera, diskoan aplikatutako $\mathrm{P}_{0}$ beroaren eta beroa aplikatzen den $t$ denboraren araberakoa izateaz aparte, diskoa inguratzen duen materialaren propietate termikoen araberakoa ere izango da. Horrela, zenbat eta bero espezifiko bolumetriko eta eroankortasun termiko altuagoak izan, orduan eta gutxiago eta motelago berotuko da diskoa. Gustafsson-en arabera [17], sentsorearen $\Delta \mathrm{T}$ tenperatura-igoerak erlazio lineala dauka t denbora adimentsionalarekin (1):

$$
\Delta T(\tau)=K \cdot D(\tau)=\frac{P_{0}}{\pi^{\frac{3}{2}} \cdot a \cdot \lambda} \cdot D(\tau)
$$

Denbora adimentsionala saiakuntzaren iraupenarekin, diskoaren diametroarekin eta neurtutako materialaren a difusibitate termikoarekin dago erlazionatuta (2).

$$
\tau=\sqrt{\frac{t \cdot \alpha}{a^{2}}}
$$

Beraz, problema ebazteko, iterazio-prozesu bat planteatu behar da, $\mathrm{D}(\mathrm{t})$ funtzioak $\Delta \mathrm{T}$ tenperatura-igoerarekin erlazio lineala izateko $\lambda$-k eta $\alpha-\mathrm{k}$ hartu beharreko balioak lortzeko.

Bukatzeko, mortero gogortuaren konpresio-erresistentzia neurtu zen, UNE-EN 1015-11:2000/A1:2007 arauari jarraikiz, 0,5 kN/s zama-abiadura ezarriz, probeta apurtu arte. Aztertutako mortero bakoitzaren dentsitatearen, urak eskura duen porositatearen eta makurdura-tentsioaren balio esanguratsuak hiru probetetan eginiko hiru saiakuntzetan lortutako batezbestekoa eta desbiderapen estandarra kalkulatuz lortu dira. Ultrasoinuen hedapen-abiaduran, aldiz, mortero bakoitzean hamabi balio daude batezbestekoa eta desbiderapen estandarra lortzeko, lau saiakuntza egin baitziren probeta bakoitzeko. Era berean, propietate termikoen kasuan, hiru saiakuntza egin zirenez probeta bakoitzean, bederatzi balio zeuden balio esanguratsua kalkulatzeko. Azkenik, konpresio-erresistentziaren kasuan, saiakuntza suntsikorra izanda, sei probeta erdi zeudenez, sei baliorekin kalkulatu ziren. 


\section{EMAITZAK ETA EZTABAIDA}

Lehenik, kareharri-harea ordezkatzeko erabili den harea berde kopuruaren arabera alderatu dira morteroak (1-6 irudiak). 1. irudian ikus daitekeen bezala, harea berdearen igoerak eta ur kantitatearen gorakadak erlazio lineala dute. Bestalde, nahasketan gehitutako urak eta porositateak erlazio garbia dute: gauza jakina da morteroari ura eransteak areagotu egiten duela haren porositatea. Ondorioz, porositatearen igoera handiena kareharri-harearik gabeko morteroan lortzen da (\% 83). Ultrasoinuei dagokienez (2. irudia), porositatean ikusitako joeraren kontrakoa gertatzen da. Harea berdearen erabilera handitu ahala, murriztu egiten da ultrasoinuen abiadura. Hemen ere kareharririk gabeko morteroan lortzen da abiadura-murrizketa handiena (\% 31). Emaitza biak koherenteak dira, porositatea areagotzeak oztopatu egiten baitu uhin ultrasonikoen ibilbide zuzena, haien igorpenaren eta jasotzearen arteko denbora handituz. Propietate termikoetan, joera berdina ikusten da (ikus 3. eta 4. irudiak): harea berdearen erabilerak murriztu egiten ditu eroankortasun termikoa eta bero espezifikoak, eta kareharririk gabeko morteroetan gertatzen da murrizketa handiena: berriro ere $\% 31$, bi kasuetan. Ildo berean, 5. eta 6 . irudietan ikus daitekeen bezala, harea berdea erabiltzean ahuldu egiten da materiala, txikitu egiten baitira makurdura- eta konpresio-erresistentziak, \% 61eko murrizpen maximoa emanez bi kasuetan, kareharririk gabeko morteroetan berriz ere. Nahiz eta erresistentziak nabarmen murriztu, \% 50eko ordezkapenarekin morteroak konpresioarekiko duen erresistentziak gainditu egiten du egitura-hormigoiei eskatzen zaien gutxieneko balioa. Bestalde, \% 100eko ordezkapena duten morteroek gainditu egiten dute egitura-erantzukizuna duten fabrika-obrak eraikitzeko araudiak ezarritako gehieneko erresistentzia ere.

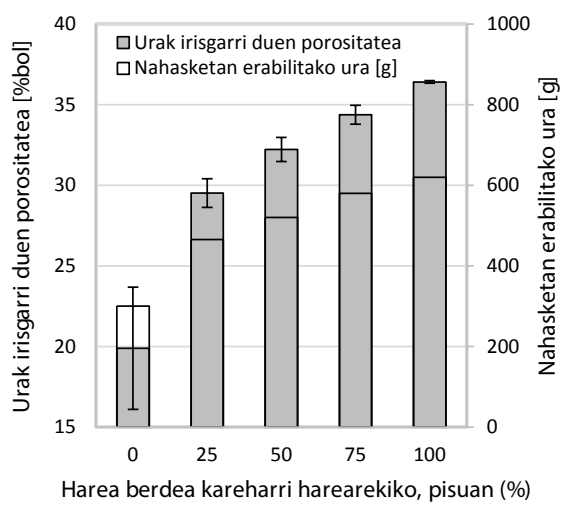

1. irudia. Ur kantitatea eta porositatea $v s$ erabilitako harea berde kopurua.

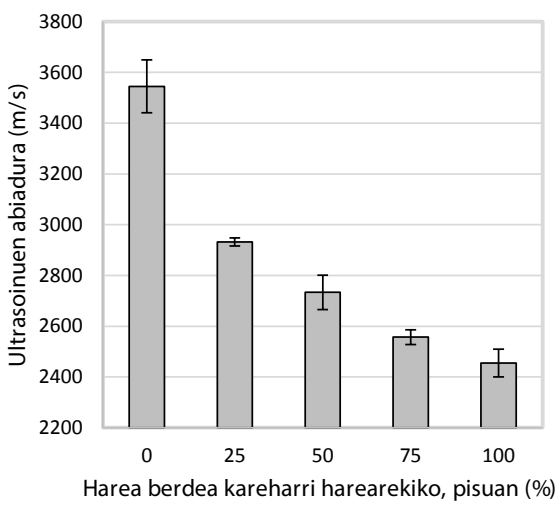

2. irudia. Ultrasoinuen hedapenabiadura $v s$ erabilitako harea berde kopurua. 


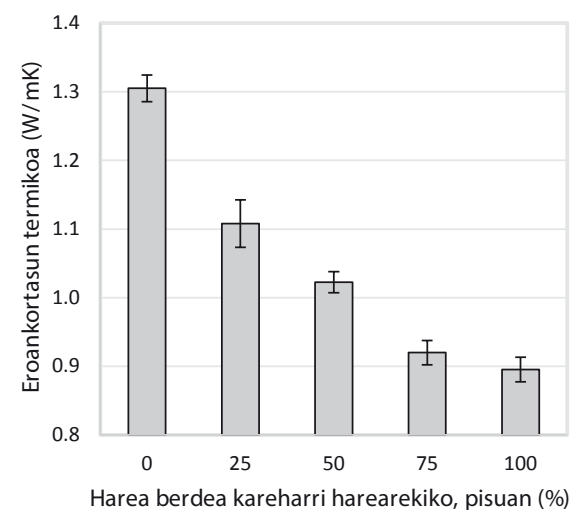

3. irudia. Eroankortasun termikoa $v s$ erabilitako harea berde kopurua.

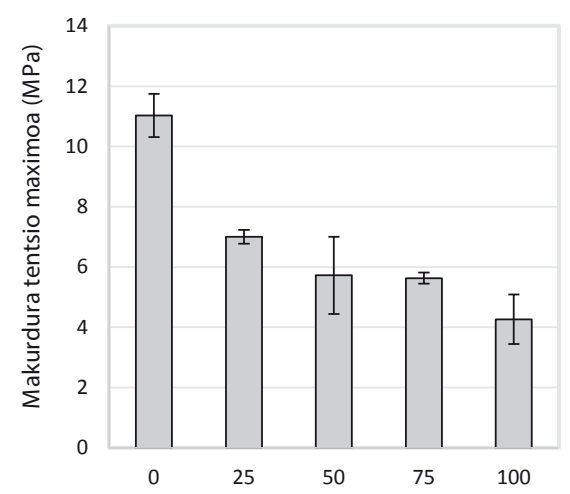

Harea berdea kareharri harearekiko, pisuan (\%)

5. irudia. Makurdura-erresistentzia vs erabilitako harea berde kopurua.

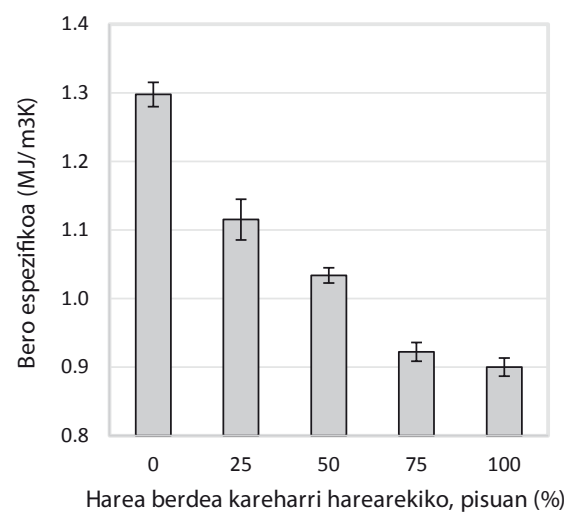

4. irudia. Bero espezifikoa $v s$ erabilitako harea berde kopurua.

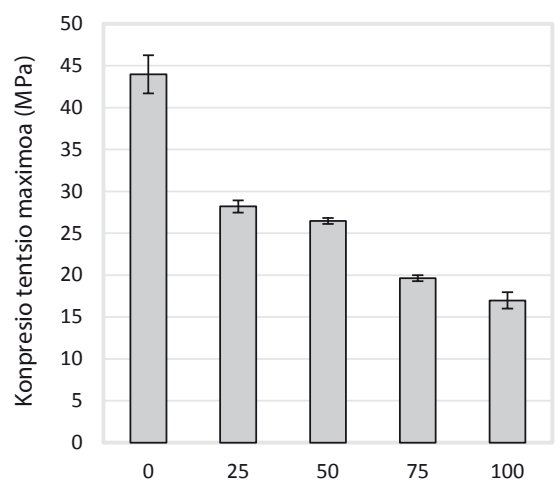

Harea berdea kareharri harearekiko, pisuan (\%)

6. irudia. Konpresio-erresistentzia vs erabilitako harea berde kopurua.

Kareharri-harea galdaketako harea berdez ordezkatzeak morteroen propietateetan duen eragina aztertu ondoren, argi geratzen da propietate guztiek joera berdintsua dutela. Beraz, bistan da erlazionatuta daudela. Galdaketako hareak duen bentonita-edukiagatik, eta horrek ura xurgatzeko duen ahalmenagatik, askoz ur gehiago behar da morteroetan loditasun bera lortzeko. Alde batetik, gauza jakina da morteroetan ur kopurua handitzeak porositatea handitzen duela. Bestalde, bentonita buztin hedagarria izanik, bere bolumena nabarmen handitzen da urarekin nahastean. Kasu honetan, bentonitak xurgatutako urak handitu egiten du bentonitak morteroan okupatzen duen bolumena. Morteroa sikatzean, ura lurrundu eta irtetean, bentonita 
ezin izango da uzkurtu, morteroaren matrizean atxikita egongo delako; hortaz, airea geratu egingo da, eta porositatea handitu.

Hortik aurrera, aztertutako beste propietate guztien beherakada justifika daiteke. Ultrasoinuak, airean, motelago hedatzen dira solidoetan baino. Beraz, morteroaren barnean zenbat eta poro gehiago egon, uhin sonikoa orduan eta gehiago desbideratu beharko da, egin beharreko ibilbidea luzatuz, neurtutako denbora areagotuz eta ultrasoinuen hedapen-abiadura efektiboa murriztuz. Propietate termikoei dagokienez, efektua nahiko antzekoa da. Airearen eroankortasun termikoa eta bero espezifiko bolumetrikoa oso baxuak direnez, airez betetako ganbera hermetiko isolatu txikiak sortzen dira isolatzaile termikoak fabrikatzeko. Morteroetan, gauza bera gertatzen da: airearen eroankortasun termikoa eta bero espezifiko bolumetrikoak arbuiagarriak dira morteroen beste osagai guztien propietateen aldean. Nahiz eta poro guztiak ez izan guztiz hermetikoak, airearen mugimendua nahiko mugatuta dago. Ondorioz, isolatzaile termikoetan gertatzen den bezala, zenbat eta porositate altuagoa izan, orduan eta eroankortasun termiko eta bero espezifiko baxuagoak izango ditu.

Kasu partikular honetan, ordea, harearen aldaketak eragin zuzena izango du morteroaren eroankortasun termikoan ere, morteroaren osagai bat aldatu egiten baita. Kareharriaren propietate termikoak eta galdaketako harea berdearen gehiengoa hartzen duen silize-harearen eroankortasun termikoa ez dira berdinak. Hasiera baten, silize-harearen partikulek kareharri-harearen partikulek baino eroankortasun termiko altuagoa izan ohi dute beren barnean [18]. Hori dela eta, kareharriaren ordez galdaketako harea berdea erabiltzeak igo egin beharko luke eroankortasun termikoa, baina kontrakoa gertatzen denez, argi dago porositatearen igoerak eragin nabarmenagoa duela. Bentonitak duen efektuaz aparte, kontuan hartu behar da galdaketako harea sartzeak bi agregakin nahastuen granulometrian izango duen eragina ere. $\mathrm{Fu}-$ ller-en kurba idealak agregakinen partikulen artean aire minimoa izateko partikula-tamaina bakoitzean izan beharreko proportzioa zehazten du. Horrela, Fuller-en kurbatik zenbat eta gehiago urrundu, orduan eta aire gehiago geratuko da harearen partikulen artean, eta zementua eta ura nahastean sortutako pastak bete beharko du hori. 7. irudiak aztertutako bost kasuetan agregakinak duen granulometria eta Fuller-en granulometria aurkezten ditu, alderaketa errazteko. Kareharriaren kurba Fuller-en kurbaren azpitik dagoenez, ideala izango litzatekeena baino partikula fin gutxiago ditu. Bestetik, galdaketako harea berdeak, tamaina handienetan $(>1 \mathrm{~mm}$, gutxi gorabehera), proportzioa larregizkoa da, Fuller-en kurbaren gainetik baitoa, baina tamaina txikietan, kareharrian bezala, partikula finen falta dauka. Are gehiago, galdaketako hareak tamaina txikienen gabezia areagotzen du kareharria ordezkatzean, kareharriak berak baino fin gutxiago baitauka. Ondorioz, handitu egiten da agregakinaren partikulen artean geratzen den aire-proportzioa, eta horrek areagotu egiten du morteroetan izango den porositatea. 


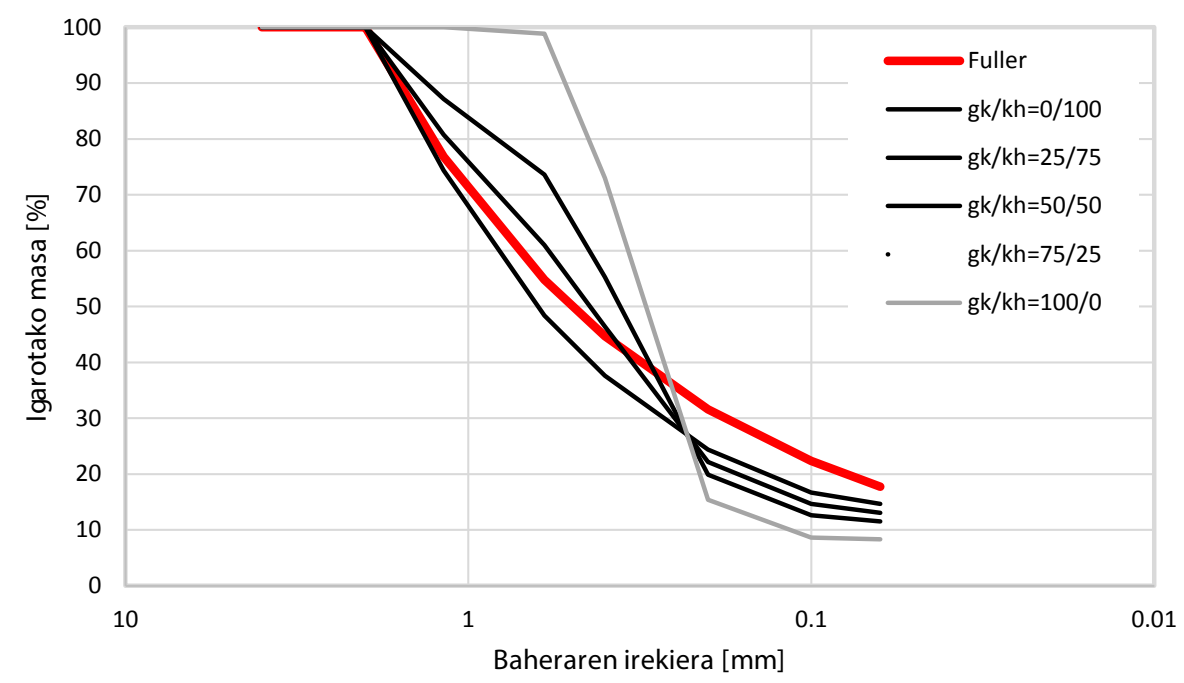

7. irudia. Agregakin konbinazio desberdinak vs Fuller-en kurba ideala.

\section{ONDORIOAK}

Artikulu honetan, galdaketako harea birziklatua erabiltzeak mortero autokonpaktatzaileen propietate fisiko, termiko eta mekanikoetan duen eragina aztertzen da. Horretarako, morteroetan normalean erabiltzen den kareharri-harearen ordez, galdaketako harea berdea erabiliko da, hainbat ehunekotan: \% 0 (kareharri-harea bakarrik), \% 25, \% 50,\% 75 eta \% 100 (galdaketako harea berdea bakarrik). Mortero gogortuen porositatea, ultrasoinuen hedapen-abiadura, eroankortasun termikoa, bero espezifiko bolumetrikoa eta makurdura- eta konpresio-erresistentziak aztertu ondoren, hurrengo ondorioetara iritsi gara:

- Harea berdea gehitzeak agregakina Fuller-en kurbatik urruntzen duenez, aire-tarte gehiago bete beharko du morteroan zementuak eta urak osatutako pastak. Ondorioz, morteroaren porositatea areagotu egingo da.

- Galdaketako harea berdeak duen bentonita-edukia dela eta, ur gehiago behar da morteroan loditasun bera lortzeko, eta horrek handitu egiten du morteroaren porositatea. Horretarako, bi mekanismotan oinarrituko da. Alde batetik, bentonitak ura xurgatzen duenez, zementuak epe luzera ur gehiago izango du eskura, zementuak eta urak osatzen duten pastaren porositatea handituz, eta ondorioz, morteroarena. Bestetik, bentonitak ura xurgatzean jasaten duen bolumen-handitzeak morteroa sikatzean hutsik geratuko diren tarteak sortzen ditu, porositatea handituz. 
- Porositatea handitzeak txikitu egiten ditu morteroaren beste propietate guztiak:

- Ultrasoinuen hedapen-abiadura murrizten du, soinua airean abiadura txikiagoan joaten baita solidoetan baino.

- Eroankortasun termikoa eta bero espezifiko bolumetrikoa txikitzen ditu, airearen bi propietate horien balioak morteroa osatzen duten beste osagai guztien balioak baino bi ordena baxuagoak baitira.

- Makurdura- eta konpresio-erresistentziak murrizten ditu, porositatea handitzeak dakarren sekzio erresistente efektiboaren murrizketa dela eta.

Galdaketako harea berdeak, nahiz eta murriztu egiten dituen morteroaren propietateak, izango luke erabilpenik exijitu beharreko erresistentzia mekanikoa baxua den eta morteroaren eroankortasun termikoa murriztea interesgarria den kasuetan: zolatu eta estalkietan, nibelatze-kapa moduan; hormigoizko blokeak egiteko, hormigoi-blokeen edo adreiluen artean mortero gisa erabiltzeko, etab.

\section{ESKER ONAK}

Artikulu hau UPV/EHUk finantzatuta eta Eusko Jaurlaritzako Hezkuntza Sailari esker argitaratu da. Eskerrak eman behar zaizkie halaber SHIF2RAIL Joint Technology Initiative-ri, HORIZON2020 programa europarraren barnean IN2TRACK2 (H2020-S2R-CFM-IP3-01-2018 Ref: 826255) eta IN2TRACK3 (S2R-CFM-IP3-01-2020 Innovation Action, Ref: 101012456) proiektuak finantzatzeagatik; Eusko Jaurlaritzari, ELKARTEK2019 deialdiko GOLIAT2 proiektuan emandako laguntzagatik [KK-2019-00023] eta ikerketa-lantaldeei emandako IT919-16 eta IT1314-19 laguntzengatik. Azkenik, FAGOR EDERLAN S. Coop.-i ere eskerrak eman nahi dizkiogu, emandako hareagatik eta, oro har, eskainitako laguntzagatik.

\section{BIBLIOGRAFIA}

[1] Da Costa Reis D, Mack-Vergara Y, John VM. 2019. «Material flow analysis and material use efficiency of Brazil's mortar and concrete supply chain». Journal of Industrial Ecology; 23:1396-409.

[2] Schneider M, Romer M, Tschudin M, Bolio H. 2011. «Sustainable cement production-present and future». Cement and Concrete Research; 41:642-50.

[3] Gheni AA, Alghazali HH, ElGawady MA, Myers JJ, Feys D. 2019. «Durability properties of cleaner cement mortar with by-products of tire recycling». Journal of Cleaner Production; 213:1135-46. 
[4] Kaewunruen S, Li D, Chen Y, Xiang Z. 2018. «Enhancement of dynamic damping in eco-friendly railway concrete sleepers using waste-tyre crumb rubber». Materials; 11.

[5] Madrid M, Orbe A, Carré H, García Y. 2018. «Thermal performance of sawdust and lime-mud concrete masonry units». Construction and Building Materials; 169:113-23.

[6] Santamaría A, Orbe A, San José JT, González JJ. 2018. «A study on the durability of structural concrete incorporating electric steelmaking slags». Construction and Building Materials;161:94-111.

[7] Liu B, Guo J, Zhou J, Wen X, Deng Z, Wang H et al. 2020. «The mechanical properties and microstructure of carbon fibers reinforced coral concrete». Construction and Building Materials;249.

[8] Silva RV, DE BRITO J, DHIR RK. 2019. «Use of recycled aggregates arising from construction and demolition waste in new construction applications». Journal of Cleaner Production;236.

[9] Villoria SÁEz P, Osmani M. 2019. «A diagnosis of construction and demolition waste generation and recovery practice in the European Union». Journal of Cleaner Production;241.

[10] Asociación de Fundidores de País VAsCo y NAVARRa. 2017 «Problemática actual de las arenas a nivel local y europeo». http://www.life-ecosandfill.eu/_ movil/files/9115/1032/7037/2._Jornada_CESFS_9911_17_AFV.pdf

[11] Siddique R, Noumowe A. 2008. «Utilization of spent foundry sand in controlled low-strength materials and concrete». Resour Conserv Recycl;53:27-35.

[12] Siddique R, Singh G. 2011. «Utilization of waste foundry sand (WFS) in concrete manufacturing». Resour Conserv Recycl;55:885-92.

[13] Dash MK, Patro SK, Rath AK. 2016. «Sustainable use of industrial-waste as partial replacement of fine aggregate for preparation of concrete - A review». International Journal of Sustainable Environment;5:484-516.

[14] Bhardwaj B, Kumar P. 2017. «Waste foundry sand in concrete: A review». Construction and Building Materials;156:661-74.

[15] GediK A, Hilmi Lav A, Aysen Lav M. 2018. «Investigation of alternative ways for recycling waste foundry sand: An extensive review to present benefits». Canadian Journal of Civil Engineering;45:423-34.

[16] Srivastava A, Singh SK. 2020. «Utilization of alternative sand for preparation of sustainable mortar: A review». Journal of Cleaner Production;253.

[17] GuSTAFSSON SE. 1991. «Transient plane source techniques for thermal conductivity and thermal diffusivity measurements of solid materials». Rev Sci Instrum;62:797-804.

[18] Borinaga-Treviño R, Pascual-Muñoz P, Castro-Fresno D, Del CozDíAz JJ. 2013. «Study of different grouting materials used in vertical geothermal closed-loop heat exchangers». Applied Thermal Engineering;50:159-67. 